Pesq. Vet. Bras. 35(Supl.1):27-32, dezembro 2015 DOI: $10.1590 / \mathrm{S} 0100-736 \mathrm{X} 2015001300006$

\title{
Perfil bioquímico sérico de bezerros de origem leiteira aleitados com dietas líquidas alternativas ${ }^{1}$
}

\author{
Kátia T. de L. Lopes ${ }^{2}$, Renata N. de Lima², Ana P.P. de Assis², Maria V.F.G. de Miranda², \\ Jamile M. Ferreira ${ }^{3}$, Hélia M. de S. Leite ${ }^{2}$, Dorgival M. de Lima Júnior ${ }^{4}$ \\ e Patrícia de O. Lima ${ }^{5 *}$
}

\begin{abstract}
Lopes K.T.L., Lima R.N., Assis A.P.P., Miranda M.V.F.G., Ferreira J.M., Leite H.M.S., Lima Junior D.M. \& Lima P.O. 2015. [Serum biochemistry profile of dairy calves fed with alternative liquid diets.] Perfil bioquímico sérico de bezerros de origem leiteira aleitados com dietas líquidas alternativas. Pesquisa Veterinária Brasileira 35(Supl.1):27-32. Departamento de Ciências Animais, Universidade Federal Rural do Semiárido, Av. Francisco Mota 572, Bairro Costa e Silva, Mossoró, RN 59625-900, Brazil. E-mail: pattlima@ufersa.edu.br

Metabolic profile is used as routine monitoring for the diagnosis of metabolic disorders, nutritional deficiencies, and as a preventive of subclinical disorders, in addition to research health issues and performance of a herd. In this context, the aim of this study was to evaluate the influence of different liquid diets containing whey cheese and colostrum on the serum biochemistry profile of calves. Twenty-four crossbred calves from dairy herds in the region, distributed in a completely randomized design with three treatments and eight replicates: $\mathrm{LI}=$ Whole milk (control); $\mathrm{LS}=50 \%$ Whole milk $+50 \%$ cheese whey in nature; $\mathrm{SC}=70 \%$ of cheese whey in natura $+30 \%$ Colostrum. Weekly blood samples by jugular puncture were collected in the morning, before the supply of liquid diet and two hours after eating this. The serum concentrations of the evaluated parameters differ between treatments, but without compromising animal performance. Thus, the use of whey associated with colostrum presents itself as a viable cost reduction with feeding calves, since possible nutritional deficits caused by differences in liquid diets are supplied by solid food form, not affecting the profiles of the metabolites related to serum protein and energy status.
\end{abstract}

INDEX TERMS: Lactation, metabolic profile, milk replacer, nutritional status, serum parameters, calves.

RESUMO.- O perfil metabólico é utilizado como monitoramento rotineiro para o diagnóstico de transtornos metabólicos, deficiências nutricionais e como preventivo de transtornos subclínicos, além da pesquisa de problemas

\footnotetext{
${ }^{1}$ Recebido em 17 de junho de 2015.

Aceito para publicação em 29 de novembro de 2015.

${ }^{2}$ Programa de Pós-Graduação em Ciência Animal, Universidade Federal Rural do Semiárido (Ufersa), Av. Francisco Mota 572. Bairro Costa e Silva, Mossoró, RN 59625-900, Brasil. E-mails: ktatylima@yahoo.com, renatanayhara@yahoo.com.br, pinheiropaula87@hotmail.com, mviviannefreitas@hotmail.com, helialeite22@hotmail.com

${ }^{3}$ Departamento de Análises Clínicas e Toxicologia, Faculdade de Farmácia, Odontologia e Enfermagem, Universidade Federal do Ceará, Rua Alexandre Baraúna 949, Bairro Rodolfo Teófilo, Fortaleza, CE 60430-160, Brasil.E-mail: jamilemagalhaes@yahoo.com.br

${ }^{4}$ Universidade Federal de Alagoas, Campus Arapiraca, Av. Manoel Severino Barbosa s/n, Bom Sucesso, Arapiraca, AL 57309-005, Brasil. E-mail: juniorzootec@yahoo.com.br

${ }^{5}$ Departamento de Ciências Animais, Universidade Federal Rural do Semiárido (UFERSA), Av. Francisco Mota 572, Costa e Silva, Mossoró, RN 59625900, Brasil. *Autor para correspondência: pattlima@ufersa.edu.br
}

de saúde e de desempenho de um rebanho. Neste contexto, o objetivo do presente trabalho foi avaliar a influência de diferentes dietas líquidas contendo soro de queijo e colostro sobre os perfis dos metabólitos séricos de bezerros durante a fase de aleitamento. Foram utilizados 24 bezerros mestiços provenientes de rebanhos leiteiros da região, distribuídos em delineamento inteiramente casualizado com três tratamentos e oito repetições: LI = Leite integral (controle); $\mathrm{LS}=50 \%$ Leite integral $+50 \%$ de Soro de queijo in natura; $\mathrm{SC}=70 \%$ de Soro de queijo in natura $+30 \%$ Colostro. Semanalmente foram coletadas amostras de sangue por punção jugular externa, no período da manhã, antes do fornecimento da dieta líquida e duas horas após a ingestão desta. As concentrações dos parâmetros séricos avaliados diferiram entre os tratamentos, porém sem comprometer o desempenho dos animais. Desse modo, a utilização de soro de queijo associado ao colostro apresenta-se como forma viável de redução de custos com aleitamento de bezerros, visto que possíveis déficits causados pelas diferenças nu- 
tricionais das dietas líquidas são supridos pelos alimentos sólidos, não afetando os perfis dos metabólitos séricos relacionados ao status protéico e energético.

TERMOS DE INDEXAÇÃO: Aleitamento, parâmetros séricos, perfil metabólico, status nutricional, sucedâneos.

\section{INTRODUÇÃO}

A criação de bezerros em regime de aleitamento natural ou artificial eleva o custo de produção do leite, especialmente quando o leite integral é fornecido por longos períodos, ao invés de destinar-se ao consumo humano e transformar-se em receita para o produtor (Rocha et al. 1999). Neste aspecto, a utilização de sucedâneos lácteos na alimentação de bezerros pode reduzir o custo final desses animais. 0 uso de sucedâneo tem como vantagens, além da parte econômica devido ao menor preço quando comparado com o leite integral, há a possibilidade de aumento na quantidade de leite a ser comercializada pelo produtor. Entretanto, a qualidade do sucedâneo, principalmente a fonte proteica, é o fator determinante para a obtenção de resultados semelhantes aos observados com o fornecimento do leite integral (NRC 2001).

Devido à grande disponibilidade, bem como oferecimento a baixo custo, o soro de queijo e o colostro, apresentam-se como excelentes alternativas ao leite integral, pois além de serem alimentos ricos em nutrientes, não apresentam fatores antinutricionais. No entanto, características próprias de cada um desses produtos devem ser levadas em consideração quando se busca a correta nutrição animal. Quanto ao soro de queijo, a necessidade de suplementação proteica e alta porcentagem de lactose têm levado muitos autores a estudarem seus níveis de associação ao leite integral (Fontes et al. 2006, Lima et al. 2012). A possibilidade de associá-lo ao colostro, alimento proteico rico em gordura, no entanto pobre em lactose, pode ser um campo de estudo promissor, que possibilite ampliar ainda mais o potencial de aproveitamento do soro de forma ainda mais vantajosa economicamente.

Segundo Mendes et al. (2005), o monitoramento de alguns parâmetros sanguíneos favorece a investigação de ingredientes ainda pouco conhecidos representando um importante auxílio na avaliação dos status nutricional no qual se encontram os mesmos. 0 perfil metabólico é utilizado como monitoramento rotineiro para o diagnóstico de transtornos metabólicos, deficiências nutricionais e como preventivo de transtornos subclínicos, além da pesquisa de problemas de saúde e de desempenho de um rebanho (Duffield \& Leblanc 2009). Nesse contexto, a avaliação do status nutricional pode ser abordada mediante a determinação da concentração de alguns metabólitos sanguíneos, sendo que os parâmetros avaliativos mais utilizados têm sido principalmente, proteínas plasmáticas, albuminas, ureia, triglicerídeos e colesterol. 0 perfil bioquímico poderá fornecer informações importantes sobre o metabolismo energético, proteico e mineral, além de avaliar funções hepática, renal, pancreática, hormonal, óssea e muscular (Mendonça 2007). O lipidograma não tem sido utilizado freqüentemente e de forma adequada, principalmente devido a escassez de estudos que procurem estabelecer os valores de referência para os animais criados sob condições brasileiras e a interrelação de suas alterações com as diversas doenças (Pogliani \& Birgel Junior 2007), daí a importância de se conhecer as variações fisiológicas dos constituintes séricos de bezerros em fase de crescimento e esclarecer alguns pontos ainda obscuros.

Assim, objetivou-se com esta pesquisa avaliar o perfil metabólito sérico de bezerros de origem leiteira submetidos a diferente sistemas de aleitamento com sucedâneos contendo soro de queijo e colostro até os 60 dias de vida.

\section{MATERIAL E MÉTODOS}

0 experimento foi desenvolvido na Universidade Federal Rural do Semiárido, Mossoró, RN (05¹1'15”S e 37²0'39”W, a 16 m de altitude). 0 clima da região, segundo a classificação de Köppen, é do tipo BSwh', seco e muito quente. Foram utilizados 24 bezerros machos, mestiços de Holandês x Zebu (mestiço local originário do cruzamento de raças zebuínas, cuja composição é desconhecida).Os tratamentos avaliados foram: LI, leite integral (controle); LS, $50 \%$ leite integral $+50 \%$ soro e queijo in natura; e SC, $30 \%$ colostro $+70 \%$ soro de queijo in natura. 0 colostro utilizado foi adquirido ao longo do experimento de propriedades leiteiras da região, e armazenado sob congelamento. 0 soro foi armazenado em freezer durante, no máximo, 36 horas. Cerca de duas horas antes do fornecimento, as dietas foram descongeladas em banho-maria e oferecidas em temperatura ambiente.

Os animais foram adquiridos com $5 \pm 3$ dias de vida, em seguida foram identificados e alojados em baias individuais de alvenaria, com cerca de $10 \mathrm{~m}^{2}$, equipadas com baldes individuais para fornecimento de água, ração comercial para bezerros e feno de Tifton85 (Cynodon spp.). Até o décimo dia de vida, os animais permaneceram recebendo leite integral na quantidade de quatro litros, fornecido duas vezes ao dia (às 8 e 16 horas). Os animais do tratamento controle permaneceram nessa dieta até o desaleitamento. Já os demais foram submetidos a um período de adaptação que teve duração de 10 dias, quando receberam suas respectivas dietas (LS: leite + soro e SC: soro + colostro) gradativamente, de forma que a mudança da dieta causasse menor impacto sobre o trato digestivo dos animais. Aos 20 dias de idade, teve início o período experimental de coleta de dados que se estendeu até os 60 dias, quando os animais foram desaleitados. Durante esse período todos os grupos foram alimentados com 4 litros de dieta líquida em duas refeições diárias.

Os parâmetros de desempenho avaliados foram consumo de matéria seca do feno e concentrado, avaliados diariamente durante o período experimental através do método oferta/sobra tendo-se ajustado a quantidade fornecida para atingir 10\% de sobra, em comparação ao consumo do dia anterior. Amostras da dieta sólida foram retiradas para posterior análise no Laboratório de Nutrição Animal da Universidade Federal Rural do Semiárido, conforme Silva \& Queiroz (2002), visando determinar teores de matéria seca, matéria mineral, proteína bruta, extrato etéreo, fibra insolúvel em detergente ácido e fibra insolúvel em detergente neutro (Quadro 1). Pesagens semanais também foram realizadas, sempre pela manhã antes do fornecimento da dieta líquida, a fim de acompanhar o ganho de peso dos animais.

Para a análise dos parâmetros séricos, durante o período experimental, foram coletadas, semanalmente, amostras de sangue por punção da veia jugular externa, em tubos do tipo vacutainer, sem adição de anticoagulantes, no período da manhã, antes do fornecimento da dieta líquida (pré-prandial) e duas horas após a ingestão desta (pós-prandial). Cerca de 60 minutos depois, os tu- 
Quadro 1. Composição químico-bromatológica das dietas fornecidas aos bezerros

\begin{tabular}{lcc}
\hline & Concentrado & Feno \\
\hline Matéria seca & 94,78 & 94,64 \\
Matéria mineral (\%MS) & 9,86 & 7,85 \\
Proteína bruta (\%MS) & 18,98 & 7,33 \\
Extrato etéreo (\%MS) & 5,62 & 1,77 \\
FDN $^{\mathrm{a}}(\% \mathrm{MS})$ & 36,78 & 75,01 \\
FDA $^{\mathrm{b}}$ (\%MS) & 6,00 & 36,78
\end{tabular}

a Fibra em detergente neutro, ${ }^{\mathrm{b}}$ Fibra em detergente ácido.

bos foram centrifugados a 5rpm, durante 20 minutos e, em seguida, com o auxílio de um pipetador automático, o soro foi retirado e distribuído, uniformemente, em tubos tipo ependorff, devidamente identificados, conservados sob refrigeração e transportados para o Laboratório de Bioquímica Clínica do Departamento de Análises Clínicas e Toxicológicas da Faculdade de Farmácia, Enfermagem e Odontologia - UFC onde se procederam as análises.

As concentrações plasmáticas de colesterol, triglicerídeos, creatinina, proteínas séricas totais, albumina e ureia foram determinadas conforme as recomendações técnicas encontradas nos kits comerciais (Bioclin), em analisador bioquímico pelo método colorimétrico, realizando-se três repetições por amostra.

0 delineamento experimental foi o inteiramente casualisado com três tratamentos e oito repetições. Os dados de parâmetros de consumo, ganho de peso e parâmetros séricos foram submetidos a análise de variância com medida repetida no tempo com o peso corporal inicial dos bezerros sendo utilizado como co-variável. As análises foram realizadas com o auxílio do pacote estatístico SAS (version 9.0, SAS Institute Inc., Cary, NC). Para efeito de comparação de médias, foi utilizado o teste de Tukey, com nível de significância de $5 \%$. As médias das semanas foram submetidas a análise de regressão polinomial quando necessário.

\section{RESULTADOS E DISCUSSÃO}

0 consumo de matéria seca dos animais que receberam as dietas substitutivas foi superior aos animais do tratamento controle $(\mathrm{P}<0,05)$, no entanto, os ganhos de peso diário e total não foram afetados (Quadro 2). Estes resultados não se assemelham aos observados por Lima et al. (2013) e Azevedo et al. (2013) ao avaliar dietas a base de soro de queijo e silagem de colostro diluído em água, respectivamente, no aleitamento de bezerros. Castro et al. (2004) também relataram maior consumo total de matéria seca de animais que consumiram colostro fermentado, em comparação a animais alimentados com leite, em razão da deficiência energética em virtude dos baixos níveis de lactose.

Quadro 2. Parâmetros de consumo de matéria seca (MS; kg/ dia) e ganho de peso $(\mathrm{kg})$ de bezerros recebendo leite integral (LI), leite integral + soro de queijo (LS) e soro de queijo + colostro (SC) como dieta líquida

\begin{tabular}{lllllllll}
\hline Variável & \multicolumn{3}{c}{ Dietas líquidas } & & EPM & \multicolumn{3}{c}{ Pr $<$ F } \\
\cline { 2 - 3 } \cline { 5 - 7 } & & LI & LS & SC & & DL & DL(S) & S \\
\hline
\end{tabular}

Consumo de matéria 0,465 b 0,600 a 0,692 a $0,036 \quad 0,001 \quad 0,880<0,001$ seca total

Ganho médio diário $\quad 0,35 \mathrm{a} \quad 0,31 \mathrm{a} \quad 0,46 \mathrm{a} \quad 0,143 \quad 0,202$ Ganho de peso total 17,27 a 15,32 a 22,48a $1,532 \quad 0,202$

\footnotetext{
$\overline{a, b}$ Médias acompanhadas por letras iguais, não diferem significativamente pelo teste Tukey a $5 \%$ de significância, DL = efeito da dieta líquida DL (S) = efeito da semana dentro de dieta líquida $\mathrm{S}=$ efeito da semana.
}

O consumo de matéria seca total apresentou aumento linear entre as semanas, conforme a equação de regressão $y=31,13+180,4 x\left(R^{2}=0,98\right)$. Este aumento se deu exclusivamente ao maior consumo de matéria seca proveniente das dietas sólidas, já que a quantidade de dieta líquida fornecida permaneceu a mesma durante todo o período experimental. Tal fato é atribuído ao aumento das necessidades nutricionais dos animais com a idade devido ao maior peso corporal e amadurecimento do trato gastrointestinal em termos anatômicos e fisiológicos, permitindo o aproveitamento da dieta sólida fornecida.

Os parâmetros de ganho de peso não diferiram entre as dietas testadas, apesar do maior consumo de matéria seca pelos animais que receberam as dietas substitutivas, o que pode ter ocorrido devido aos efeitos aditivos e/ou substitutivos do maior consumo de concentrado. A média de ganho de peso foi menor que o observado por Azevedo et al. (2013) avaliando o desempenho de bezerros holandeses recebendo silagem de colostro como dieta líquida. 0 ganho médio diário do tratamento que fornecia soro associado ao colostro $(0,46 \mathrm{~kg} / \mathrm{dia})$ apresentou-se próximo aos obtidos com fornecimento de colostro por Modesto et al. (2002) e Castro et al. (2004), 0,48 kg/dia e 0,49 kg/dia, respectivamente. Ambos também não encontraram diferenças significativas para o ganho de peso entre os tratamentos com colostro e leite integral.

A caseína é a principal proteína do leite integral e tem importante função na correta alimentação de animais pré-ruminantes, pois possui a propriedade única de coagular-se no abomaso na presença da renina. Segundo Orskov (1992), os coágulos são gradualmente quebrados nas horas seguintes à alimentação, resultando no suprimento contínuo de nutrientes para o animal, apesar de estes terem acesso ao leite apenas duas a três vezes por dia. No entanto, durante o processo de fabricação do queijo, a caseína presente no leite fica retida na coalhada, sendo praticamente inexistente no soro de queijo. Assim, dietas para pré-ruminantes contendo grandes quantidades de soro de queijo resultam em um coágulo inconsistente, incapaz de nutrir os animais por períodos mais prolongados de tempo, fazendo com que estes complementem sua alimentação buscando os alimentos sólidos. Apesar do consumo de matéria seca dos animais ter sido superior, pode-se afirmar que as dietas líquidas substitutivas foram satisfatórias dentro do proposto para a sua função, que é promover a nutrição dos animais, com menor custo, sem comprometer o desenvolvimento corporal destes. Outro fator que pode ser considerado como uma vantagem destas é o fato de que os animais passarão para a fase de recria mais adaptados fisiologicamente para aproveitar as dietas sólidas, já que o maior consumo deste alimento favorece o desenvolvimento ruminal.

As concentrações médias de glicose não apresentaram diferenças significativas (Quadro 3), no entanto os valores pré-prandiais foram inferiores aos referenciados para bovinos lactentes por Pogliani \& Birgel Junior (2007) de 62,6 a $88,3 \mathrm{mg} / \mathrm{dL}$, porém próximos aos encontrados por Lima et al. (2012) para bezerros mestiços. Os resultados mostraram indicativo de hipoglicemia, o que não se pode atribuir às dietas testadas, pois os resultados foram semelhantes à 
Quadro 3. Média e erro padrão da média (EPM) dos parâmetros séricos de bezerros recebendo leite integral (LI), leite integral + soro de queijo (LS) e soro de queijo + colostro (SC) como dieta líquida

\begin{tabular}{|c|c|c|c|c|c|c|c|}
\hline & \multicolumn{3}{|c|}{ Dietas Líquidas } & \multirow[t]{2}{*}{ EPM } & \multicolumn{3}{|c|}{$\operatorname{Pr}<\mathrm{F}$} \\
\hline & LI & LS & SC & & DL & $\mathrm{DL}(\mathrm{S})$ & $\mathrm{S}$ \\
\hline \multicolumn{8}{|l|}{ Glicose (mg/dL) } \\
\hline Pré-prandial & $42,24 a$ & $47,94 a$ & $46,34 a$ & 1,07 & 0,076 & 0,144 & 0,001 \\
\hline Pós-prandial & $83,35 a$ & $82,44 a$ & $84,15 a$ & 1,80 & 0,940 & 0,116 & 0,092 \\
\hline \multicolumn{8}{|c|}{ Colesterol (mg/dL) } \\
\hline Pré-prandial & $82,19 a$ & $69,56 b$ & $90,03 a$ & 2,16 & 0,002 & 0,105 & 0,214 \\
\hline Pós-prandial & $78,36 \mathrm{ab}$ & $71,00 \mathrm{~b}$ & $89,03 a$ & 2,06 & 0,007 & 0,149 & 0,570 \\
\hline \multicolumn{8}{|c|}{ Triglicerídeos (mg/dL) } \\
\hline Pré-prandial & $21,62 b$ & $15,70 \mathrm{c}$ & $26,04 a$ & 0,76 & $<0,001$ & 0,587 & 0,184 \\
\hline Pós-prandial & $20,91 \mathrm{ab}$ & $18,28 b$ & $25,03 a$ & 0,92 & 0,023 & 0,120 & 0,107 \\
\hline \multicolumn{8}{|c|}{ Albumina (mg/dL) } \\
\hline Pré-prandial & $2,67 a$ & $2,39 b$ & $2,61 \mathrm{ab}$ & 0,04 & 0,036 & 0,801 & 0,807 \\
\hline Pós-prandial & $2,67 a$ & $2,45 b$ & $2,45 b$ & 0,04 & 0,040 & 0,895 & 0,460 \\
\hline \multicolumn{8}{|c|}{ Proteína Total (mg/dL) } \\
\hline Pré-prandial & $6,72 \mathrm{a}$ & $5,95 b$ & $6,56 a$ & 0,07 & $<0,001$ & 0,225 & 0,869 \\
\hline Pós-prandial & $6,61 \mathrm{a}$ & $5,53 b$ & $6,31 \mathrm{a}$ & 0,10 & $<0,001$ & 0,471 & 0,401 \\
\hline \multicolumn{8}{|l|}{ Ureia (mg/dL) } \\
\hline Pré-prandial & $29,45 a$ & $20,64 b$ & $30,48 a$ & 9,24 & $<0,001$ & 0,551 & 0,123 \\
\hline Pós-prandial & $29,08 a$ & $20,36 b$ & $29,19 a$ & 8,55 & $<0,001$ & 0,506 & 0,089 \\
\hline \multicolumn{8}{|c|}{ Creatinina (mg/dL) } \\
\hline Pré-prandial & $1,05 a$ & $0,86 \mathrm{~b}$ & $0,97 a b$ & 0,02 & $<0,001$ & 0,259 & $<0,001$ \\
\hline Pós-prandial & $0,88 a$ & $0,60 \mathrm{~b}$ & $0,90 \mathrm{a}$ & 0,03 & $<0,001$ & 0,968 & 0,216 \\
\hline
\end{tabular}

dieta controle. De acordo com Kuhne et al. (2000), a concentração plasmática de glicose em bezerros depende diretamente da quantidade ingerida e da concentração de lactose presente na secreção láctea, o que não se comprovou neste estudo, visto que as diferenças nas concentrações de lactose dos componentes utilizados nas dietas líquidas, refletiu em dietas semelhantes quanto ao aporte energético, considerando a glicose como indicador do status energético. Os níveis semanais de glicose sérica sofreram efeito significativo da semana $(\mathrm{P}<0,05)$, com comportamento polinomial de acordo com a equação: $y=1,082 x^{2}-7,902 x+61,67$; $\mathrm{R}^{2}=0,603$ (Fig.1), onde na primeira semana de avaliação, os animais apresentaram média superior as demais, o que deve estar relacionado ao maior consumo e aproveitamento da matéria seca proveniente da dieta sólida. É provável que as diferenças observadas no consumo de alimentos sólidos pode ter tido efeito compensatório, complementan-

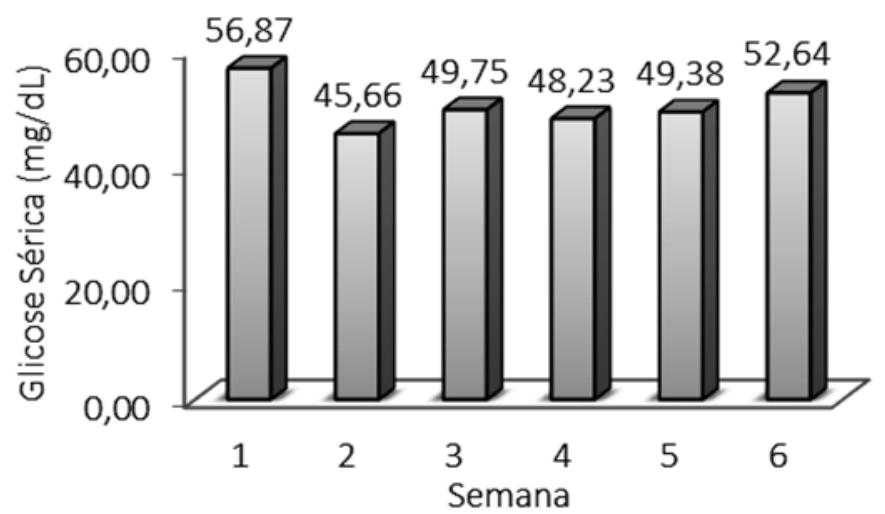

Fig.1. Níveis semanais de glicose sérica de bezerros até os 60 dias. do o consumo de energia proveniente da dieta líquida. No entanto, há discordância entre os pesquisadores quanto a real capacidade de a glicemia refletir o status energético, porém, há uma recomendação geral da avaliação deste parâmetro no perfil metabólico.

A concentração sérica de colesterol total diferiu significativamente em função das dietas líquidas $(\mathrm{P}<0,05)$, onde os animais do tratamento soro+leite apresentaram as menores médias em relação aos demais tratamentos. Verificou-se ainda que seus valores encontram-se abaixo dos observados por Smith (2009) que relatou como normais teores de colesterol que oscilassem entre 90 e $170 \mathrm{mg} / \mathrm{dL}$. Já Pogliani (2006) recomenda para bezerros lactentes com até três meses de idade, valores de referencia de 86,5 a 120,8mg/ dL. Os animais do tratamento que continha colostro possivelmente, mantiveram seus níveis elevados devido ao maior fluxo de lipoproteínas no plasma, devido a ingestão e transporte mais intenso de gordura (VLDL, LDL e HDL) entre os intestinos e o fígado e deste para o tecido adiposo. Hammon \& Blum (1998) também observaram maiores níveis plasmáticos de colesterol em bezerros que receberam colostro suplementar até os sete dias de vida, e atribuíram este fato ao maior ingestão de gordura proveniente do colostro. Já os níveis séricos de colesterol dos animais que receberam soro+leite, podem ter sido influenciados pela menor concentração de gordura na dieta, além do prejuízo na qualidade do coágulo formado devido aos menores teores de caseína. Lucci (1989) afirma que o coágulo de boa resistência, permite o fluxo contínuo e lento de nutrientes para o intestino, onde são digeridos e absorvidos, o que influi positivamente na digestão das gorduras, uma vez que pequenas porções de lipídios permanecem retidas no estômago, 
permitindo ação mais prolongada da esterase pré-gástrica sobre os ácidos graxos. Com relação aos níveis de triglicerídeos, os animais do tratamento que continha colostro apresentaram médias superior aos demais $(\mathrm{P}<0,05)$. No geral, as médias encontradas neste trabalho estão dentro do intervalo considerado normal de acordo com Pogliani \& Birgel Junior (2007): entre 16,3 a $34,8 \mathrm{mg} / \mathrm{dL}$. Este resultado reflete a maior re-síntese de triglicerídeos nos enterócitos, derivados do maior consumo de extrato etéreo presentes nas dietas desses animais (líquida e solida), adicionado a este fato, a maior síntese hepática de ácidos graxos a partir do maior fluxo de glicose proveniente dos altos teores de lactose oriunda da presença de soro de queijo em grandes quantidades $(70 \%)$, pode ter contribuído para os resultados obtidos.

Os níveis séricos de albumina diferiram estatisticamente entre os tratamentos, com menores médias para os animais que receberam as dietas substitutivas, especialmente o tratamento soro+leite $(\mathrm{P}<0,05)$. Comportamento semelhante foi observado para os níveis séricos de proteína total, o que se atribui ao fato desta ser a mais abundante das proteínas do plasma sanguíneo, constituindo cerca de 50 a 65 $\%$ do total (Contreras, 2000). Os valores encontrados para albumina estão próximos dos referenciados por Leal et al. (2003) e Radostits et al. (2002), entre 2,5 e 3,0mg/dL. Lima et al. (2012) avaliando os parâmetros séricos de bezerros recebendo soro de queijo na dieta líquida, não verificaram diferenças significativas entre este o tratamento controle, no entanto, encontraram valores médios para albumina inferior aos apresentados neste trabalho. Em seus estudos Reis et al. (2007) encontraram valores dentro da amplitude normal de variação de 5,57 a 6,94g/dL para proteína total, esses valores estão próximos aos encontrados neste estudo. A albumina é sintetizada no fígado e sua concentração pode ser alterada pelo aporte proteico na ração, o mesmo vale para a ureia. No entanto, a albumina é indicador útil, quando o déficit proteico é mais prolongado, o que se explica por sua meia vida de aproximadamente 20 dias, além da manifestação do déficit de albumina ser mais tardia, também é menos intensa, se comparada com a ureia (Contreras 2000). Assim, em caso de deficiência proteica, os valores séricos de ureia seriam afetados mais rapidamente, o que foi observado neste trabalho, onde o tratamento leite+soro apresentou menor média para os níveis séricos de ureia quando comparado com os demais tratamentos $(\mathrm{P}<0,05)$.

Em função da qualidade prejudicada do coágulo formado, grande quantidade de nutrientes chegam rapidamente ao intestino delgado logo após a alimentação, sobrecarregando o sistema digestivo e provocando menor digestão e absorção dos nutrientes, o que pode ter acarretado perdas intestinais da proteína da dieta, resultando em menores teores séricos de proteína. Além disso, a alta concentração de lactose presente no soro de queijo pode provocar diarréia, o que intensificaria essas perdas protéicas. Essas afirmações concordam com Luca \& Reis (2001) que apresentaram como prováveis causas de níveis mais baixos de proteína total a deficiência de proteína na dieta, insuficiência hepática, aproveitamento inadequado da proteína ingerida, hemorragias e perda da proteína intestinal ou renal. No entanto, Baracat et al. (1995) verificaram um efeito positivo da presença de colostro na dieta sobre a produção de proteínas séricas totais, incluindo a fração albumina. Além disso, tem sido atribuído papel de proteção local aos anticorpos existentes no colostro fornecido suplementarmente aos bezerros, os quais protegeriam a mucosa intestinal levando a menores incidências de diarréia (Daniele et al. 1994, Berge et al. 2009) e consequentemente, menores perdas de proteínas.

A dieta também afetou de forma significativa os níveis de creatinina sérica dos bezerros, onde os animais do tratamento soro+leite apresentaram menores médias que os demais $(\mathrm{P}<0,05)$. As médias encontradas neste trabalho estão dentro da faixa encontrada por Feitosa et al. (2009) de 0,3 e $1,7 \mathrm{mg} / \mathrm{dL}$, para bezerros entre o $16^{\circ}$ e $30^{\circ}$ dias. Os intervalos de referência preconizados por Kaneko et al. (1997) para bovinos são de 1 a $2 \mathrm{mg} / \mathrm{dL}$. Os valores neste trabalho estão abaixo do encontrado por Fagliari et al. (1998) que avaliaram os níveis de creatinina em bezerros lactentes (46 e 180 dias) das raças Nelore e Holandês, com médias de 1,34 e $1,37 \mathrm{mg} / \mathrm{dL}$, respectivamente. Embora não tenham sido observadas diferenças estatísticas no ganho de peso dos animais, é possível que as diferenças numéricas verificadas entre o tratamento soro+leite em comparação aos demais possa ter afetado os níveis de creatinina sérica, já que de acordo com Borba et al. (2011) a creatinina é um produto metabólico da degradação da creatina-fosfato no músculo, sendo sua produção relativamente constante e dependente da massa muscular. Assim, problemas renais podem representar valores aumentados de creatinina, e redução nesses valores podem ser devido a uma severa perda muscular (Meyer et al. 1995).

Como são inúmeras as variáveis mensuráveis no perfil metabólico, é fundamental a utilização de dados de referência para interpretação dos resultados obtidos, no entanto, existem dificuldades quanto à utilização dessa ferramenta, devido à falta de referência adequada, e quando se trata de bezerros mestiços há escassez de estudos sobre a bioquímica clínica. Os dados obtidos neste trabalho para os parâmetros séricos estão próximos ao limite inferior, na escala de normalidade quando comparados as referências observadas na literatura, possivelmente por se tratarem de animais mestiços, com alta incorporação de características zebuínas em sua formação, que devido a características adaptativas, apresentam seus limites para metabólicos sanguíneos, especialmente os relacionados ao status protéico, mais baixos que animais puros (Vettorato et al. 2012, Jenet et al. 2006, Rekwot et al. 1989).

\section{CONCLUSÃO}

A utilização de soro de queijo associado ao colostro apresenta-se como forma viável de redução de custos com aleitamento de bezerros, visto que possíveis déficits causados pelas diferenças nutricionais das dietas líquidas são supridos pelos alimentos sólidos, não afetando os perfis dos metabólitos séricos relacionados ao status protéico e energético.

Agradecimentos.- Ao Banco do Nordeste, pelo financiamento do projeto. 


\section{REFERÊNCIAS}

Azevedo R.A., Araújo L., Coelho S.G., Faria Filho D.E., Duarte E.R. \& Geraseev L.C. 2013. Desempenho de bezerros alimentados com silagem de leite de transição. Pesq. Agropec. Bras. 48(5):545-552.

Baracat R.S., Machado Neto R., Daniele C., Bessi R. \& Packer I.U. 1995. Fornecimento prolongado de colostro e proteção passiva em bezerros recém-nascidos. Sci. Agric. 52(3):537-542.

Berge A.C.B., Besser T.E., Moore D.A. \& Sischo W.M. 2009. Evaluation of the effectsof oral colostrum supplementation during the first fourteen days on the health and performance of preweanded calves. J. Dairy Sci. 92(1):286-295.

Borba A.J., Rocha M.G.M., Silva M.F., Tibúrcio D.T.S., Pereira S.A.L., Reis L.C. \& Thedei Junior G. 2011. Dieta hiperlipídico-proteica utilizada para emagrecimento induz obesidade em ratos. Revta Nutr. 24(4):519-528.

Castro A.L.M., Campos W.E. \& Mancio A.B. 2004. Desempenho e rendimento de carcaça de bezerros alimentados com colostro fermentado, associado ao óleo de soja e zeranol. Arq. Bras. Med. Vet. Zootec. 56:193-201.

Contreras P. 2000. Indicadores do metabolismo proteico utilizados nos perfis metabólicos de rebanhos, p.9-23. In: González F.H.D., Barcellos J.O., Ospina H. \& Ribeiro L.A.O. (Eds), Perfil Metabólico em Ruminantes: seu uso em nutrição e doenças nutricionais. Gráfica da UFRGS, Porto Alegre.

Daniele C., Machado Neto R., Baracat R.S. \& Bessi. R. 1994. Efeito de diferentes manejos de fornecimento prolongado de colostro sobre os níveis de proteína e albumina séricas e desempenho de bezerras recém-nascidas. Sci. Agric. 51(2):381-388.

Duffield T.F. \& Leblanc S.J. 2009. Interpretation of serum metabolic parameters around the transition period. Southwest Nutrition and Management Conference, Tempe, AZ, p.106-114.

Fagliari J.J., Santana A.E., Lucas F.A., Campos Filho E. \& Curi P.R. 1998. Constituintes sangüíneos de bovinos lactantes, desmamados e adultos das raças Nelore (Bos indicus) e Holandesa (Bos taurus) e de bubalinos (Bubalus bubalis) da raça Murrah. Arq. Bras. Med. Vet. Zootec. 50(3): 263-271.

Feitosa F.L.F., Peiró J.R., Mendes L.C.N., Cadioli F.A., Camargo D.G., Yanaka R., Bovino F. \& Perri S.H.V. 2009. Determinação do perfil boquímico renal sérico de bezerros holandeses e mestiços, na região de Araçatuba/SP. Anais do VIII Congresso Brasileiro de Buiatria. Ciênc. Anim. Bras. 1:255259.

Fontes F.A.P.V., Coelho S.G., Lana A.M.Q., Costa T.C., Carvalho A.U., Ferreira M.I.C., Saturnino H.M., Reis R.B. \& Serrano A.L. 2006. Desempenho de bezerros alimentados com dietas líquidas à base de leite integral ou soro de leite. Arq. Bras. Med. Vet. Zootec. 58(2):212-219.

Hammon H.M. \& Blum J.W. 1998. Metabolic and endocrine traits of neonatal calves are influenced by feeding colostrum for different duration or only milk replacer. J. Nutr. 128:642-632.

Jenet A., Fernandez-Rivera S., Tegegne A., Wettstein H.R., Senn M., Saurer M., Langhans W. \& Kreuzer M. 2006. Evidence for different nutrient partitioning in Boran (Bos indicus) and Boran $\mathrm{x}$ Holstein cows when re-allocated from low to high or from high to low feeding level. J. Vet. Med. 53:383-393.

Kaneko J.J., Harvey J.W. \& Bruss M.L. 1997. Clinical Biochemistry of Domestic Animals. 5th ed. Academic Press, San Diego, p.857-883.

Kuhne S., Hammon H.M., Bruckmaier R.M., Morel C., Zbinden Y. \& Blum J.W. 2000. Growth performance, metabolic and endocrine traits, and intestinal absorptive capacity in neonatal calves fed either colostrum or milk replacer at low and high intensities. J. Anim. Sci. 78(3):609-620.

Leal M.L.R., Benesi F.J., Lisbôa J.A.N., Coelho C.S. \& Mirandola R.M.S. 2003. Proteinograma sérico de bezerras sadias, da raça holandesa, no primeiro mês pós nascimento. Braz. J. Vet. Res. Anim. Sci. 40:138-145.
Lima P.O., Cândido M.J.D., Queiroz M.G.R., Ferreira J.M., Modesto E.C., Lima R.N., Gomes J.M.C. \& Aquino R.M.S. 2012. Parâmetros séricos de bezerros submetidos a diferentes tipos dietas líquidas. Revta Bras. Saúde Prod. Anim. 13(2):529-540.

Lima P.O., Lima R.N., Miranda M.V.F.G., Pereira M.W.F., Melo F.B.A., Cordeiro L.A.V., Assis A.P.P. \& Leite H.M.S. 2013. Desenvolvimento dos estômagos de bezerros recebendo diferentes dietas líquidas. Ciência Rural 43(4):716-721.

Luca G.C. \& Reis B.F. 2001. Espectrofotometria de proteínas totais em plasma de sangue bovino por análise em fluxo. Sci. Agric. 59(2):251-256.

Lucci C.S. 1989. Bovinos Leiteiros Jovens: nutrição, manejo, doenças. Nobel, São Paulo. 372p.

National Research Council 2001. Nutrient Requirement in Dairy Cattle. 7th ed. National Academy of Science, Washington, DC. 381p.

Meyer D.I., Coles E.H. \& Rich L.J. 1995. Medicina de Laboratório Veterinário: interpretação e diagnóstico. Roca, São Paulo, p.47-52, 92,108,146.

Mendes A.R., Ezequiel J.M.B., Galati R.L. \& Feitosa J.V. 2005. Desempenho, parâmetros plasmáticos e características de carcaça de novilhos alimentados com farelo de girassol e diferentes fontes energética, em confinamento. Revta Bras. Zootec. 34(2):962-702.

Mendonça A.J. 2007. Avaliação hematológica, bioquímica e hemostática de bezerros Brahman provenientes de produção in vitro (PIV) e bezerros Brahman de produçao in vivo. Tese de Doutorado, Faculdade de Medicina Veterinária e Zootecnia, Universidade Estadual Paulista, Botucatu, SP. 107p.

Modesto E.C., Mancio A.B., Menin E., Cecon P.R. \& Detmann E. 2002. Desempenho produtivo de bezerros desmamados precocemente alimentados com diferentes dietas líqüidas com utilização de promotor de crescimento. Revta Bras. Zootec. 31(1):429-435.

Orskov E.R. 1992. Protein Nutrition in Ruminants. Academic Press, Aberdeen. $175 \mathrm{p}$.

Pogliani F.C. 2006. Valore de referências e influências de fatores etários, sexuais e da digestão no lipograma de bovinos da raça holandesa, criados no Estado de São Paulo. Dissertação de Mestrado em Clínica Veterinária, Faculdade de Medicina Veterinária e Zootecnia, Universidade de São Paulo, São Paulo/SP. 134p.

Pogliani F.C. \& Birgel Junior E.H. 2007. Valores de referência do lipidograma de bovinos da raça Holandesa, criados no Estado de São Paulo. Braz. J. Vet. Res. Anim. Sci. 44:373-383.

Radostits O.M., Gay C.C., Blood D.C. \& Hinchcliff K.W. 2002. Clínica Veterinária: um tratado de doenças dos bovinos, ovinos, suínos, caprinos e equinos. 9a ed. Guanabara Koogan, Rio de Janeiro. 1737p.

Reis M.C., Costa J.N. \& Peixoto A.P.C. 2007. Efeito da idade e da suplementação oral com o acetato de DL-alfa-tocoferol sobre os níveis séricos de vitamina E sobre o proteinograma de bezerros. Revta Bras. Saúde Prod. Anim. 8(3):152-161.

Rekwot P.I., Oyedipe E.O., Akerejola O.O., Voh Jr A.A. \& Dawuda P.M. 1985. Serum biochismistry of zebu bulls and their frisian crosses fed two planes of protein. Brit. Vet. J. 145:85-88.

Rocha E.O., Fontes C.A.A., Paulino M.F., Pereira J.C. \& Ladeira M.M. 1999. Influência da idade de desmama e de início do fornecimento do volumoso a bezerros sobre a digestibilidade de nutrientes e o balanço de nitrogênio, pós-desmama. Revta Bras. Zootec. 28(1):143-147.

Smith B.P. 2009. Large Animal Internal Medicine. 4th ed. Mosby Elsevier, St Louis. 1821p.

Silva D.J. \& Queiroz A.C. 2002. Análises de Alimentos: métodos químicos e biológicos. $3^{\text {a }}$ ed. Editora UFV, Viçosa. 235p.

Vettorato E.D., Costa M.C., Flaiban K.K.M.C., Vidotto O., Balarin M.R.S. \& Lisbôa J.A.N. 2012. Variação de proteínas séricas em bezerros das raças nelore e holandesa do nascimento até seis meses de vida. Semina, Ciênc. Agrár. 33(2):3181-3190. 